\title{
The Great Oxidation Event: An Expert Discussion on the Causes, the Processes, and the Still Unknowns
}

\author{
Moderator: Frances Westall ${ }^{1}$ \\ Participants: Ariel Anbar, ${ }^{2}$ Woody Fischer, ${ }^{3}$ and Lee Kump ${ }^{4}$
}

Dr. Frances Westall (FW): Let's begin with each of you giving an overview as to the importance of biogenic processes in the rise of oxygen-oxygenic photosynthesis. Lee, would you like to begin?

Dr. Lee Kump (LK): What is really interesting about the history of atmospheric oxygenation is that there is this event or interval of change from an anoxic Archean atmosphere to an oxygenated post-Archean atmosphere (Holland, 1994). When we think about the causes of the rise of oxygen and we think about the Great Oxidation Event, it is really a fundamental change in the way the Earth system functioned. It is a new state; it is the oxygenated state that is distinct from the anoxic state, and it is nonreversible.

That suggests to me really only two possibilities: that it was driven by biological innovation, and that the timing of that transition is linked to that biological innovation, in other words, the origin of oxygenic photosynthesis; or that it is the result of a threshold effect for some sort of monotonic change in either oxygen supply or oxygen demand, crossing over that threshold where the potential falls below the potential supply of oxygen, and we go into that oxygenated state.

These are not new ideas with me, of course, and probably the one person who defined that most clearly was Heinrich (Dick) Holland, who unfortunately recently passed away. But he set the stage for all of us in terms of our thinking about this balance between oxygen supply and demand.

Presuming that the origin and spread of oxygenic photosynthesis significantly predated the apparent oxygenation of the atmosphere from the sulfur isotope record, it is about looking for either a monotonic decline in the oxygen sink or an increase in the supply of oxygen to the atmosphere (Farquhar et al., 2000). So that is what I have been focusing on.

The other part of it that I have always found very interesting is that the transition seemed to be happening right around the Archean-Proterozoic boundary. At first in the earlier days when Dick Holland in particular was compiling geological evidence for the rise of oxygen, it looked like the rise of oxygen postdated the Archean-Proterozoic boundary at 2.5 billion years ago. Now it looks like that transition is very close to the Archean-Proterozoic line, so looking for this long-term driver for monotonic change and the timing seeming to get honed in on the Archean-Proterozoic transition, I have always looked for a change in the solid Earth dynamics that is linked to that, because the ArcheanProterozoic boundary was defined based on geological evidence for the stabilization of continental cratons.

That is what ultimately led Mark Barley and me to look at that issue of changes in style of tectonics at the ArcheanProterozoic boundary, and ultimately focus on the style of volcanism (Kump and Barley, 2007). This was, again, the result of Holland pointing out that in modern volcanic systems, the oxygen demand from the release of fluids, gases of subaerial volcanoes was significantly less than that from the release of fluids from submarine volcanoes.

We looked at the distribution in time of subaerial versus submarine volcanism. We looked in particular at a previous compilation by Prokoph and colleagues of the large igneous province emplacement through time and hypothesized that submarine volcanism dominated the Archean (Prokoph et al., 2004). In fact, that is exactly what we found.

Our story that developed was that there was a significant change in the proportion of subaerial volcanoes and an increase in the proportion of subaerial volcanoes with the stabilization of the continents. The ability to support largestrata volcanoes and volcanism in the post-Archean led to a decline in the oxygen demand and thus allowed for this state transition from an anoxic Archean to an oxic post-Archean.

The details of the history of atmospheric oxygen evolution are much more complicated than that, but the sulfur isotope record, the non-mass-dependent fractionation seems to indicate that the atmosphere did not revert to an anoxic state once it became oxygenated. So for me, we crossed some sort of threshold, and we are thinking about a change in the style of tectonism driven by the progressive heat loss from the planet, leading to a change in the style of plate tectonics and the growth of stabilization of continents that led to this change in volcanism.

FW: That is a great introduction and helps set the scene. Ariel, would you like to add something here to this introductory phase of the discussion?

Dr. Ariel Anbar (AA): Lee covered most of the ground very nicely. For my part, I got pulled into this question, and I

\footnotetext{
${ }^{1}$ Director of Research, Centre de Biophysique Moléculaire, Orléans, France.

${ }^{2}$ School of Earth and Space Exploration, Arizona State University, Tempe, Arizona, USA.

${ }^{3}$ Division of Geological and Planetary Sciences, California Institute of Technology, Pasadena, California, USA.

${ }^{4}$ Department of Geosciences, Pennsylvania State University, University Park, Pennsylvania, USA.
} 
fell into Dick Holland's orbit, really, as an undergraduate, and it was because I was starting to learn about geoscience and I was interested in the environment and the planet. A very basic question you might ask as an undergraduate is, "Why do we have air that we can breathe?"

It became pretty apparent in talking to Dick that we were still arguing about this very basic question: why is the atmosphere what it is? Why do we have $21 \%$ oxygen today? Then talking to Dick, I learned about this phase change, essentially, in the atmosphere, that at that time he was trying to really prove the case against a fair number of doubters that before roughly 2.5 billion years ago the environment was anoxic.

On a very big-picture level I got pulled into this question because it struck me: here is a first-order question in Earth system science that you would think we would have figured out a long time ago because it is very basic and fundamental. Yet there we were, still arguing about what had actually happened.

So here we are now, 20 years or so later, and we are still arguing about what happened. Although the arguments we are having are a bit different from the ones that were going on back then. The mass-independent sulfur isotopes really have made a huge difference in the discussion. The vast majority of the community no longer argues about whether or not the atmosphere underwent this large change. When I was an undergraduate, and Lee was an undergraduate, we did still argue about it much more. So now the question is this causative question. Why did it happen, and when did it begin to happen?

Lee framed the hypotheses very nicely. There is no need for me to rehash that exactly, but I will give my biaseswhere my hypotheses tend to go. I look at the world around us today, and it is obviously an oxygenated world by any standard. But if you look around in the right places, there are plenty of anoxic pockets-you could call them antioxygen oases-where there is not oxygen, where there is biology thriving in those settings today, even though that is not typical of what we think of as the Earth's surface environment.

My bias is - and I freely admit it is a bias - that the Archean Earth, the pre-oxygenated Earth, was an Earth that was at least as complicated and interesting as today, but with a different dominant flavor. So whereas today you have $21 \%$ oxygen in the atmosphere, but you have pockets of anoxia, my bias is to think that the Archean world was a world in which you had very little oxygen in the atmosphere, but you had pockets of oxia (Anbar et al., 2007). That is not a unique idea to me.

I think I have that bias because when I was a young undergraduate I was reading what Preston Cloud had written on the idea of oxygen oases. I believe that was the way he interpreted banded iron formations-near continental margins you had high cyanobacterial activity, doing oxygenic photosynthesis and locally creating oxygenic environments that could lead to oxidation of iron. This is what I grew up with as a vision of what the Archean Earth was. And it still remains what I suspect to be the case.

The question is, now that we have strong evidence that the atmosphere did not have oxygen at that time, can we develop similarly strong evidence, or can we approach that strength of evidence, to support this notion of a very heterogeneous Archean environment where you had oxygen oases and localized oxygen production, perhaps for hun- dreds of millions of years, perhaps even for a billion or two billion years, before the accumulation of large amounts of oxygen in the atmosphere? That is where I am coming from.

The reason I am on this conversation, I suspect, is because of the so-called "whiff of oxygen" work that I and my collaborators have been involved with, which is the latest manifestation of efforts to look for evidence of oxygen production before the Great Oxygenation Event. I suspect we will dig into that a little bit more as the conversation goes on.

The other thing I will add is that part of the reason I have this bias is because, from what I can tell, what we can see, it looks like microbiology was probably already pretty richly evolved by the time of the Great Oxygenation Event. It is hard to tell because we are looking at scraps of evidence. But we certainly have good reason to think that prokaryotic metabolisms - we could argue about eukaryotic — of all sorts were probably around by then.

Again, I freely admit this is a hunch, but why should oxygenic photosynthesis have not already evolved by then? Is oxygenic photosynthesis so intrinsically more complicated than other metabolisms that it could not have been around by then? My hunch is that it was, so let us go look for evidence to see if that hunch actually can be supported or not.

FW: Thank you, Ariel. That is a good complement to what Lee had to say. What about Woody now?

Dr. Woody Fischer (WF): Lee and Ariel set up these end members really nicely. The only thing that I would add is that we understand the phenomenology, at least in some sense, of the Great Oxygenation Event, or the rise of oxygen, and we understand better the timing as we basically get a chance to study more rocks. There are a bunch of new proxies that have helped that, and in particular the multiple sulfur isotopes.

The big mechanistic question that is staring us all in the face is this: Is the evolution of oxygenic photosynthesis responsible for the timing? We need to look at changes in the solid Earth, for example, or changes in the way that the Earth made igneous rocks to better understand the mechanisms for why we see this change.

A lot of the effort that I put in has been trying to ask how well we know whether or not cyanobacteria, this group that is responsible for the evolution of biological water splitting, are they around in Archean environments? And how can we develop the best set of tests to answer that question? It is not easy.

The biggest problem is that cyanobacteria actually do not have a very good Archean fossil record. So we recognize that the oldest cyanobacterial fossils are probably about 1.9 billion years old. Then there are a variety of other structures and things that people have talked about, filamentous things. But of course, those are non-unique for cyanobacteria. Stromatolites, those are non-unique for cyanobacteria.

What we basically have now is that the way that we look for cyanobacteria is by looking for oxygen, by looking for their metabolite. We are trying to do so at concentrations that are so small that we are starting to flirt with concentrations that you might see from other processes, for example, nonoxygenic photosynthesis. It makes the problem really challenging.

It is really important that we develop these proxies that can be independent of a body fossil record that can also help 
inform when the clade is around so that we can ask the question about oxygen.

For example, if we could determine uniquely from molecular fossils that cyanobacteria are present 2.6 billion years ago, then we can really turn the question into the following: Why is it that we do or do not see products of their metabolism? Or in what environments do we see products of their metabolism? Things like that.

FW: Let me just add that Jacob Walbauer and his colleagues have been writing quite a lot about biosignatures for prokaryotes, also for eukaryotes in formations that are about 2.7 billion years old. There is one, the Fortescue Group formation, and also there are the Griqualand formations in South Africa. In one of the papers that I recently read (Waldbauer et al., 2009), he is stating from the Griqualand formations that they have also found evidence for steranes, which can only relate to eukaryotes, and this is in a 2.7billion-year-old rock.

Then there was another paper (Waldbauer et al., 2011), and he also mentions that if you have evidence for eukaryotes, they need oxygen. Therefore, there had to have been cyanobacteria around at the time, although they do not have particular evidence for the cyanobacteria.

On the other hand, in their previous paper (Waldbauer et al., 2009), regarding the 2-methylhopanoids that had been related to cyanobacteria, they realized that they could not use them as biomarkers of cyanobacteria because they were produced by other organisms.

The problem is, as Woody says, cyanobacteria are not easily fossilized, and their fossil record is not very sure. On the other hand, I wonder if one could use the size and volume of stromatolites as a possible proxy for the presence of oxygenic photosynthesizers, because if you look at the stromatolites from the early Archean formations in the Pilbara and in Barberton they are of the order of about $10 \mathrm{~cm}$ in size.

You compare them to the huge structures, for instance, at Steep Rock or elsewhere; these are structures that are of the order of meters in size, which seems to suggest that they were created by organisms that could grow rather rapidly or had easy access to nutrients, to carbon, to energy. That is something that we can discuss.

FW: We can look further at the relative influence of these processes, the timing. How can we test when the influences appeared or the extent to which these influences affected the rise of oxygen in the atmosphere? The floor is open.

AA: I would like to pick up something that Woody said and amplify it: I think that the big challenge for us here is quantitation. For those of us looking at the Archean record and trying to infer whether there was biogenic oxygen production, and as Woody said very nicely, we are stuck for the moment mostly doing this indirectly, because the molecular fossils are not as indicative as we want of cyanobacteria in particular.

So we do things like, as you mentioned, look at steranes, which are indicative of eukaryotes, which we think required oxygen for some of their biosynthetic pathways. We look at traces of redox-sensitive elements like molybdenum and things like that.

There are other lines of evidence as well. These things are contentious, but for each one you can build a pretty decent argument that a particular line of evidence is indeed evi- dence that there was some oxygen around. And each one we could argue about. But where we really get stuck is, even if you stipulate that the case is reasonable that this is evidence of oxidation-how much oxidation? And do you need to have molecular oxygen? And how much molecular oxygen? That is a really tough question.

So with the steranes, what is being shown now by Stolper, Canfield, and Waldbauer is you can produce steranes with very, very low amounts of oxygen in the environment.

WF: Nanomolar.

AA: Right. And so with the molybdenum and rhenium kind of evidence that we have developed, Dimitri Sverjensky has made the quantitative argument that the oxidizing potential needed is so low that maybe you do not need to have oxygen around. That is an interesting argument.

That is where I think one of the frontiers in all this is- to try to turn these qualitative indicators into quantitative ones and see how far you can push them in either direction. That is a big frontier that the community has to grapple with and requires a melding of the kind of analytical stuff that many of us do with some serious theoretical modeling that too few of us do.

FW: That is a very fundamental point, and also reflects perhaps the relativity. Are we dealing with a local oasis, or are we dealing with a global event?

LK: I think that is very important, because we tend to talk about the Great Oxygenation Event without specifying what environment we are referring to. Of course, in general, we are thinking about the atmosphere, but the establishment of an oxygen-rich atmosphere could have significantly postdated, as others have already mentioned, the establishment of local oxygenated environments. When you look at a microbial mat, for example, even in the absence of any oxygen in the surrounding environment, a microbial mat can generate hundreds of micromolar of oxygen concentration during the day, just to be swept away at night.

So we have actually done some modeling of that. Ellen Herman (Herman and Kump, 2005), a student of mine years ago, had a geobiology paper on modeling microbial mats, and we came to understand from doing that modeling that the microbial mat environment, the internal environment, to a first approximation does not really depend at all on the external oxygen concentration.

From Woody's point of view of detecting oxygen, I would think once there were cyanobacteria producing oxygen in microbial mats, there was in that local environment, that centimeter-thick environment, hundreds of micromolar worth of oxygen.

Then you look to the oases; we can get hundreds of nanomolar oxygen concentrations in a productive surface ocean regionally defined and then separate it from anoxic regions. So at the scale of the marine surface environment, you could have regions of so-called oxygen oases at a time when the atmosphere is essentially still anoxic.

So if and when we find these definitive indicators for oxygen in the environment, we have to take a step back and put it in its geological context, as you were mentioning, Frances, to understand-what does that mean? Was this just a microbial biofilm that had measurable oxygen concentrations in it, or was it a planktonic marine environment that probably required a much more widespread productive 
cyanobacterial population to generate even hundreds of nanomolar oxygen concentrations? Or is it really in the atmosphere?

FW: I think the question of preservation and biogenesis is really important here. When oxygenic photosynthesis first appeared, it had to be by mutation and accident, basically. But the signature would not be preserved, because any materials from the mutants, these first organisms, would be degraded and returned to the normal reducing state, that would be degraded by the heterotrophs.

Also, one of the important things mentioned is the quantification of all this, related to the individual microbial mat scale up to the local scale up to the regional scale.

AA: I will toss out one other perspective that readers may find useful. We are stuck with a historical detective story, essentially. It is rare in this game that you have silver bullets or find smoking guns. The multiple sulfur isotopes are the closest we come to that, and I think in the last few years we have realized it is not quite as strong a smoking gun as we would like it to be, but it is still very strong.

So we are left with making these arguments of parsimony that contain multiple lines of evidence, none of which is $100 \%$ indicative of whether or not there was oxygen or of the amount of oxygen. But we have to build up a case based on these multiple lines of evidence and ask ourselves, "Is this scenario to interpret this evidence, is that more reasonable or less reasonable than the alternative scenarios?"

The idea of multiple working hypotheses and weighing them against each other in terms of our judgment of what is reasonable and likely tends to be the way these arguments go. That can be very frustrating for outside observers, I think, especially from other disciplines, who are not geoscientists, who are used to more experimental science, where you can be more definitive. But that is the nature of the business.

WF: I would definitely second that. The one thing that we do really well in historical fields like this is work between multiple working hypotheses and recognize that not everything is tied up in a little bow at any given point. I would just add one thing that I think differentiates where we are at. We may not have answers to the questions we were asking 40 years ago, but we have a lot more tools, and we have recently seen a kind of explosion in terms of different types of proxies that inform this question, whether these are redoxsensitive proxies or whether they are proxies that might inform a question regarding the evolution or distribution of cyanobacteria.

Right now we are in this interval where we are going through and trying to ask: How well do these different proxies do when we are trying to apply them to rocks that are 2.5 billion years old and have complicated histories? This is an interval where someone looking from the outside might say, "These guys do not understand what's going on at all." But right now everyone is iterating between all these different things—standing on them and seeing how well they hold up.

That is certainly what we have been doing with the molecular fossils and what we are just now starting to do with multiple sulfur isotope proxies, trying to understand them better mechanistically. How do they work? How have sedi- mentary rocks recorded information about the geobiology of this interval? And so on.

LK: Another interesting development is a renewed focus on the terrestrial environment. Most of the record is in the marine environment, but when you think about redox proxies for an oxygenated atmosphere, it is, in a sense, better to be looking on land where there is not an interfering layer of a significant thickness of water that modifies that relationship between atmospheric $\mathrm{O}_{2}$ and the redox state of that local environment.

So I think not just in terms of paleosols but also in terms of some of the marine proxies, redox-sensitive elements and their isotopes that are sourced from the weathering environment, forces us to think not just about what is happening in the marine environment but what is happening on land. There is a biological side of that, as well. There are some who would advocate for a terrestrial origin for the cyanobacteria, for example. So unfortunately, terrestrial environments tend to be even more poorly preserved than marine environments. But where we have preserved terrestrial environments, paleosols, or looking at their products transported to the ocean in terms of sediments, I think that we will be learning a lot more about the global environment.

FW: I am not sure that I am aware of the latest evidence for laterites and so on on land. Can one of you discuss the earliest evidence for laterites, or paleosols?

WF: Some of the oldest of what you would call a true laterite, where iron is being retained and oxidized, are Paleoproterozoic in age, probably about 2.3 to 2.0 million years ago. Examples come from South Africa and Canada.

And another bit on that is the behavior of redox-sensitive detrital grains. They behave effectively in a binary fashion, and they follow the sulfur isotope record to the best of our ability to tell. That is to say, to the degree that we can answer the question of whether or not pyrite is being substantially weathered chemically in the terrestrial environment, that answer looks like it certainly would support the sulfur isotope record. That is, anything younger than 2.3 million years, those pyrite grains are very rare. Everything older, you can find them in fluvial sandstones and near-shore marine sandstones.

FW: The paleosols from South Africa, is this the Timeball Hill area?

WF: Timeball Hill has putative paleosols in there. It is not totally great. There are some examples that are known that are in younger rocks; where South Africa collides with Zimbabwe, there is a big mountain, and there is a whole set of red beds that are deposited across basically the whole craton.

FW: Thanks for that. To summarize our discussion, we have Ariel, who is proposing oxygen oases way before the Archean-Proterozoic rise in oxygen in the atmosphere. Lee, who is talking about the influences of mantle processes and changes in the geological evolution of the Earth, basically. And Woody, who is looking at the proxies and the variety of metabolites-the signatures of metabolites. Do you have any concluding remarks regarding these aspects?

LK: One of the things following up from my discussion, that I am sure is perplexing to the others as well-I am thinking of Ariel's whiff of oxygen as evidence, for example 
for the mobilization of molybdenum on the continents in the latest Archean time period, where the sulfur isotope record is telling us that the atmosphere is still anoxic. So we have weathering indicators for at least some exposure of minerals to oxygen that mobilizes those few elements that are more soluble under oxygenated conditions at a time when the sulfur isotopes are telling us there is no oxygen around. Resolving that apparent paradox is an important one as we try to understand this transition interval centered around 2.5 billion years ago.

AA: One potential resolution to that paradox is that these proxies are potentially sampling things on different time scales. Imagine that you have an environment that is generally anoxic, so you can produce lots of mass-independently fractionated sulfur. But occasionally you have small amounts of oxygen, perhaps episodic. It is seasonal or something like that. Perhaps it is diurnal. Perhaps it is more random than that, with small amounts of oxygen introduced to near-shore environments where you could oxidize weathering environments slightly, just enough to bring these signatures in. You can then have both of these kinds of signals coexisting, because the time scales that they are sampling or representing are somewhat different.

So one of the directions that push you into wanting to probe that idea is to try to get into higher-resolution records, essentially. To what kind of time resolution can we push the sulfur isotope record, for example? How small a variation of time can I look at? As well as variations in the atmosphere if they were there?

LK: And to that end, I would like to point out that one of the things that has happened recently is we have gotten access to quite a bit more drill core than has ever been available to study Archean and Paleoproterozoic times, and that is thanks to funding agencies like NASA and the National Science Foundation and the Agouron Institute, as well. We suddenly now have the potential to establish those higherresolution records in well-preserved materials, and some of the advances that have been made in the last 10 years have been the result of drilling on the continents for deep time.

AA: Right. And very important. Let me just make a point for nonspecialist readers. We have spent a lot of time here talking about the surface environment and the biological record and the weathering record. But as Lee pointed out in his opening, it may well be that it is the solid Earth that somehow is the driver here, the volcanism idea and so forth.

That means we need to be bringing people from the solid Earth sciences more into these conversations, people who think about tectonics, people who think about mantle processes, and there are very few who are involved in this issue. I suspect that we will be able to test some of those ideasfrom a theoretical standpoint, anyway-much more effectively if we have those kinds of interactions. That is something I am working on and I hope we will see more of in the future.

FW: That is a fantastic comment, and it actually leads into my last question, which is this: Earth is a multi-plate planet; let's say we are on an extrasolar planet, and the conditions are right for the emergence of something like oxygenic photosynthesis, but it is a one-plate planet. How would this affect the potential rise of oxygen in the atmosphere?
AA: The conventional answer to that question, and it is a very reasonable one, is that if you want to accumulate oxygen in the atmosphere, you have to bury organic carbon somehow. By oxygenic photosynthesis we mean production of oxygen and organic carbon, so you have to sequester the organic carbon, or else it re-oxidizes, and then you will not have a lot of oxygen around. Plate tectonics provides you with a nice way to do that, because you end up creating sedimentary basins where you can bury and sequester organic carbon.

I have thought about that question from a slightly different standpoint, in terms of thinking about water worldsplanets where you have no continents exposed to the surface and very deep oceans. Could you accumulate oxygen there? My working hypothesis would be no, because you do not have an easy way to bury organic carbon. I can imagine a world that is teeming with biology, teeming with oxygenic photosynthesis, but you cannot really see it very well, because it does not accumulate in the atmosphere. The oxygen recombines with organic carbon on rapid time scales.

WF: Ariel's point is a really good one, and it is one that we did not talk a lot about. But it is fundamentally that we have oxygen in the atmosphere, and the reason why is a question that involves the rock cycle. So if you do not have much of a rock cycle, you can expect things to immediately look very different.

Oxygenic photosynthesis took a long time to evolve on Earth. We recognize that in many ways the stars have to align for the right components to come together. We are talking coupled photosystems. We are talking a stronger terminal oxidant. We are talking the water-oxidizing complex. All these things are nontrivial. They were invented once and then borrowed thereafter.

LK: One other thing I will mention-I am thinking about when Ariel brought up water. There is a link between the two that James Lovelock, probably among others, has emphasized, and that is that on a planet without an oxygenated atmosphere, there is a tendency to lose hydrogen to space, which is a process ultimately of loss of water from that planet. Of course, the dire consequence of that is the dehydration of a planet, and the time scales are debatable in terms of evolutionary time scales on those planets. But the establishment of an oxygen-rich atmosphere drastically reduces the loss of hydrogen to space. So in some ways, that rise of oxygen is critical for the long-term habitability of a planet if that long-term habitability requires large water bodies like oceans.

FW: On the early planets, like earlier Mars, we do not know exactly when or how plate tectonics started out. But to my understanding, it was more like plume tectonics. Could something like plume tectonics contribute to sufficient burial of reduced carbon in surface sediments, or do we really need something like plate tectonics?

LK: Well, you need sedimentary basins, and in more of a vertical tectonic setting, basins do form, so potentially if there are oceans and areas of subsidence, you should get accumulation of sediments in those environments and the burial of organic carbon, which would allow for accumulation of oxygen.

So I think it is certainly possible, and there are other models and conflicting evidence as to when subduction initiated. And was it shallow subduction, and is that transition more a transition from shallow to deep subduction that is associated with the Archean-Proterozoic boundary? The 
oxygenation of the biosphere has been a perplexing problem for decades; for the solid Earth, geodynamic community, the onset of plate tectonics and the style of tectonics in the Archean has been sort of a nagging problem with conflicting information and pretty strongly held views by people looking at different types of data. Trying to reconcile all of that is one of the grand challenges for the solid Earth science community.

FW: Well, thanks, all of you. I have learned many things, and I certainly understand that we have quite a few challenges ahead of us.

\section{References}

Anbar, A.D., Duan, Y., Lyons, T.W., Arnold, G.L., Kendall, B., Creaser, R.A., Kaufman, A.J., Gordon, C.W., Scott, C., Garvin, J., and Buick, R. (2007) A whiff of oxygen before the great oxidation event? Science 317:1903-1906.
Farquhar, J., Bao, H., and Thiemens, M. (2000) Atmospheric influence of Earth's earliest sulfur cycle. Science 289:756-758.

Herman, E.K. and Kump, L.R. (2005) Biogeochemistry of microbial mats under Precambrian environmental conditions: a modeling study. Geobiology 3:77-92.

Holland, H.D. (1994) Early Proterozoic atmospheric change. In Early Life on Earth, edited by S. Bengtson, Columbia University Press, New York, pp 220-236.

Kump, L.R. and Barley, M.E. (2007) Increased subaerial volcanism and the rise of atmospheric oxygen 2.5 billion years ago. Nature 448:1033-1036.

Prokoph, A., Ernst, R.E., and Buchan, K.L. (2004) Time-series analysis of large igneous provinces: $3500 \mathrm{Ma}$ to present. J Geol 112:1-22.

Waldbauer, J.R., Sherman, L.S., Sumner, D.Y., and Summons, R.E. (2009) Late Archean molecular fossils from the Transvaal Supergroup record the antiquity of microbial diversity and aerobiosis. Precambrian Res 169:28-47.

Waldbauer, J.R., Newman, D.K., and Summons, R.E. (2011) Microaerobic steroid biosynthesis and the molecular fossil record of Archean life. Proc Natl Acad Sci USA 108:13409-13414. 